\title{
Emphysematous Pyelonephritis Complicating an Undetected Diabetic Female: A Case Report
}

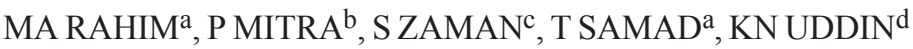

\begin{abstract}
Summary:
A case of emphysematous pyelonephritis is reported here. A middle aged Bangladeshi lady presented with fever and left loin pain. She had tachycardia, dehydration and left renal angle tenderness. Investigations revealed diabetes mellitus, left renal stone and left sided emphysematous pyelonephritis complicated by acute kidney injury. She required nephrectomy along with antibiotics. Emphysematous pyelonephritis almost exclusively occurs
\end{abstract}

\section{Introduction:}

Emphysematous pyelonephritis is an uncommon and severe form of necrotizing infection of renal parenchyma and collecting system characterized by gas formation. Patients with diabetes mellitus are the usual sufferers and rarely an episode of emphysematous pyelonephritis may unmask previously undiagnosed diabetes. ${ }^{1}$ Here we report a case of class IV emphysematous pyelonephritis ${ }^{2}$ occurring in a middle aged Bangladeshi lady.

\section{Case Report:}

A 46-year-old lady, previously not known to be diabetic, presented with 4-days history of fever, left flank pain and vomiting. She was anaemic, dehydrated, febrile (temperature $103^{\circ} \mathrm{F}$ ), tachycardic (pulse $108 / \mathrm{min}$ ) but had normal blood pressure (115/75 mm Hg). Systemic examination revealed left renal angle tenderness. Other examination findings were unremarkable.

Her random blood glucose level during admission was $21.3 \mathrm{~m} . \mathrm{mol} / \mathrm{L}$. Bed side urine showed glucose +++

a. Dr. Muhammad Abdur Rahim, Tabassum Samad, Assistant Professor, Nephrology, BIRDEM General Hospital, Dhaka, Bangladesh.

b. Dr. Palash Mitra, Assistant Registrar, Nephrology, BIRDEM General Hospital, Dhaka, Bangladesh.

c. Dr. Shahana Zaman, Junior Consultant, Cardiology, NICVD, Dhaka, Bangladesh.

d. Prof. Khwaja Nazim Uddin, Professor, Internal Medicine, BIRDEM General Hospital, Dhaka, Bangladesh.

Address of Correspondence: Dr. Muhammad Abdur Rahim, Assistant Professor, Nephrology, BIRDEM General Hospital, Dhaka, Bangladesh. Mobile: Email: muradrahim23@yahoo.com

Received: 13 Nov. 2017

Accepted: 26 Feb. 2018 in diabetic patients and rarely emphysematous pyelonephritis may unmask undetected diabetes as in the present case. Renal stone is also recognized risk factor for emphysematous pyelonephritis.

Key words: diabetes mellitus, emphysematous pyelonephritis, nephrectomy, renal stone.

(J Bangladesh Coll Phys Surg 2018; 36: 80-81) DOI: http://dx.doi.org/10.3329/jbcps.v36i2.36071

and traces of albumin. She had neutrophil leukocytosis (total white cells $19,400 / \mathrm{cmm}$ of blood with $91 \%$ neutrophils) with mild reduction in haemoglobin $(\mathrm{Hb}$ $9.8 \mathrm{gm} / \mathrm{dL})$ and normal platelets $(1,98,000 / \mathrm{cmm}$ of blood). Erythrocyte sedimentation rate (ESR) and Creactive protein $(\mathrm{CRP})$ were raised $\left(\mathrm{ESR} 67 \mathrm{~mm}\right.$ in $1^{\text {st }}$ hour and CRP $64 \mathrm{mg} / \mathrm{L}$ ). Urine routine examination showed plenty of pus cells/high power field (HPF) and red cells 1-2/HPF. Urine culture revealed significant (colony count $>1 \times 10^{5} / \mathrm{ml}$ ) growth of extendedspectrum beta-lactamase (ESBL) positive Escherichia coli. Blood culture did not show any growth. Serum creatinine was $1.9 \mathrm{mg} / \mathrm{dL}$ and glycated haemoglobin (HbAlc) was $8.1 \%$. Her antibiotic was changed from ceftazidime to meropenem ( $1 \mathrm{gm}$ every 12 hours intravenously) after receiving urine culture report.

Ultrasonogram findings were consistent with left sided emphysematous pyelonephritis with left renal stone. Non-contrast computed tomography (CT) scan revealed similar findings (Figure 1). As air extended beyond perinephric area (class IV emphysematous pyelonephritis) $)^{2}$, left nephrectomy was done. Histopathology of the resected tissue revealed acute on chronic pyelonephritis with perinephric abscess. Her post-operative period was uneventful and she was discharged on $10^{\text {th }}$ post-operative day with a normal serum creatinine level.

She is on our regular follow-up and on last follow-up visit after two and half years of nephrectomy, she is having a normal renal function (serum creatinine 1.1 $\mathrm{mg} / \mathrm{dL}$ ) and good glycaemic control with metformin $500 \mathrm{mg}$ twice daily (fasting blood glucose $6.4 \mathrm{~m} . \mathrm{mol} /$ $\mathrm{L}$ and $\mathrm{HbA} 1 \mathrm{c} 6.9 \%)$. 


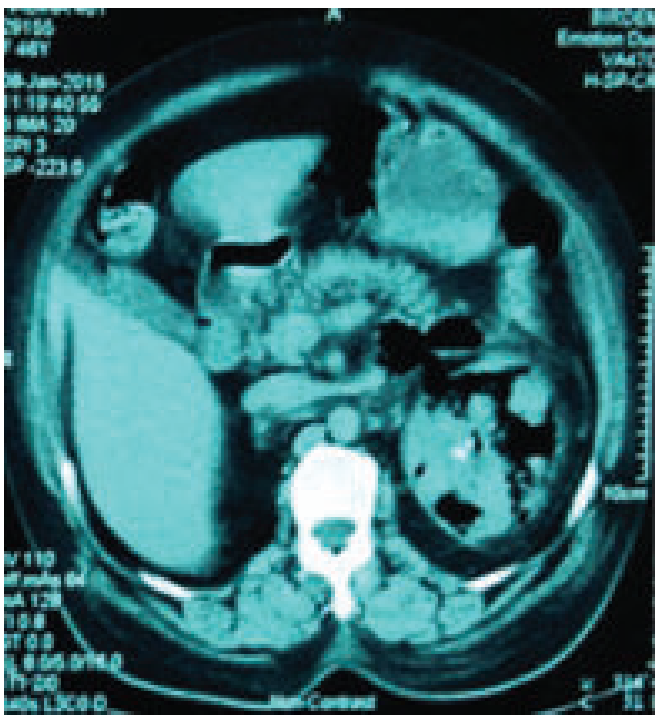

Fig.1: Non-contrast computed tomography scan showing class IV emphysematous pyelonephritis involving left kidney along with left renal stone.

\section{Discussion:}

Emphysematous pyelonephritis almost exclusively occurs among patients with diabetes mellitus. ${ }^{3-5}$ Other risk factors include renal stones, genito-urinary obstruction, chronic kidney disease, post-transplantation status etc. ${ }^{2,4}$ Fermentation of glucose by Enterobacteriaceae is the source of gas formation in emphysematous pyelonephritis. Depending up on the extension of gas in kidney(s) and perinephric areas, Huang and Tseng have classified emphysematous pyelonephritis in 4 classes. $^{2}$

Clinical presentation of emphysematous pyelonephritis includes fever with chills and rigor, loin pain and vomiting. Patients may present with pneumaturia and rarely patients may remain asymptomatic. ${ }^{5}$ Occasionally, an episode of emphysematous pyelonephritis may help in diagnosis of previously undetected diabetes mellitus ${ }^{1}$ as was true in our case and such cases sometimes may require nephrectomy. ${ }^{6}$ Neutrophil leukocytosis and high inflammatory markers are common. ${ }^{3}$ Urine culture may reveal the organism and often patients may have septicaemia.
Treatment consists of resuscitation along with intravenous antibiotics with or without surgery. ${ }^{2,3}$ Class III and more radiological classes require surgery. ${ }^{2}$ The therapeutic trends are in change and more conservative approach are followed now-a-days. ${ }^{7} \mathrm{Lu} \mathrm{Y}$ et al. have described predictors of failure in conservative management of emphysematous pyelonephritis. ${ }^{8}$ Our patient required surgery because of class IV disease and kidney stone. She recovered with combined medical and surgical treatment and remained in good health and under regular follow-up.

\section{Conclusion:}

Emphysematous pyelonephritis is an uncommon and severe infection mostly occurring among diabetic patients. Any patient with emphysematous pyelonephritis should be investigated for diabetes, if not previously diagnosed one.

\section{References:}

1. Rafailidis V, Karadimou V, Liouliakis C, Kougioumtzoglou D. Emphysematous pyelonephritis: a case report. Hippokratia 2013;17(4):373-375.

2. Huang JJ, Tseng CC. Emphysematous pyelonephritis: clinicoradiological classification, management, prognosis and pathogenesis. Arch Intern Med 2000;160:797-805.

3. Rahim MA, Ananna MA, Samad T, Chowdhury TA, HaqueWMM, Iqbal S. Emphysematous Pyelonephritis in a 32Year-Old Diabetic Female. J Enam Med Col 2015; 5(2):122-124.

4. Ubee SS, McGlynn L, Fordham M. Emphysematous pyelonephritis. BJU Int 2011;107(9):1474-1478.

5. Samad T, Rahim MA, Ananna MA, Chowdhury TA, Huq WMM, Iqbal S. Emphysematous pyelonephritis: retrospective analysis of 15 cases in a single center. Nephrology Dialysis Transplantation 2015; 30(suppl_3): iii420-iii421.

6. Nasr AA, Kishk AG, Sadek EM, Parayil SM. A Case Report of Emphysematous Pyelonephritis as a First Presentation of Diabetes Mellitus. Iran Red Cres Med J 2013; 15(12):e10384.

7. Sokhal AK, Kumar M, Purkait B, Jhanwar A, Singh K, Bansal A, et al. Emphysematous pyelonephritis: Changing trend of clinical spectrum, pathogenesis, management and outcome. Turk J Urol 2017;43(2):202-209.

8. Lu Y, Chiang B, Pong Y, Huang K, Hsueh P, Huang C, et al. Predictors of failure of conservative treatment among patients with emphysematous pyelonephritis. BMC Infectious Diseases 2014;14:418. 